\title{
Modernisasi Arsitektur Tradisional Istana Dalam Lokal Di Sumbawa (Studi Historis Arkeologi)
}

\author{
Subari $^{1}$, Anwar ${ }^{2}$ \\ Program Studi Ilmu Sejarah, Fakultas Ilmu Budaya, Institut Ilmu Sosial dan Ilmu Budaya Samawa \\ Rea \\ Email: subarisejarah@gmail.com, anwardonggo@gmail.com
}

\begin{abstract}
Abstract: The traditional architecture of the Dalam Loka Palace in Sumbawa is a historical heritage that is stored in local culture as a royal residence. This palace was built in 1885 during the reign of Muhammad Jalaluddinsyah III which was used as a resting place for the royal family. The purpose of the research is to see the history and development of palace architecture along with the renovations that do not cause a shift in values, let alone cause the loss of meaning and social function as well as the local wisdom contained in it. The method used in this research is using a qualitative descriptive approach that starts from the stages of source collection (heuristic), criticism (verification), analysis and synthesis (interpretation), and writing (historiography), observation, interviews, literature study. The results show that the modernization referred to in the traditional architecture of the Istana Dalam Loka is to carry out a thorough restoration without changing the meaning as a moral basis that is embedded in the value of the existence of the palace in local Sumbawa.
\end{abstract}

Keywords: Modernization, Traditional Architecture, Palace in Loka

\begin{abstract}
Abstrak
Abstrak Arsitektur tradisional Istana Dalam Loka di Sumbawa merupakan warisan sejarah yang tersimpan dalam budaya lokal sebagai tempat singgahsana kerajaan. Istana ini dibangun pada tahun 1885 pada masa pemerintahan Muhammad Jalaluddinsyah III yang digunakan sebagai tempat peristrahatan keluarga kerajaan. Adapun tujuan penelitian adalah untuk melihat sejarah dan perkembangan arsitektur istana seiring dengan adanya renovasi yang tidak menyebabkan terjadinya pergeseran nilai, apalagi menyebabkan hilangnya makna dan fungsi sosial serta kearifan lokal yang terkandung di dalamnya. Metode yang digunakan dalam penelitian ini adalah mengunakan pendekatan deskriptif kualitatif yang dimulai dari tahap pengumpulan sumber (heuristic), kritik (verifikasi), analisis dan sintesis (Interpretasi), dan penulisan (historiografi), observasi, wawancara, studi pustaka. Hasil penelitian menunjukan bahwa modernisasi yang dimaksud dalam arsitektur tradisional Istana Dalam Loka adalah melakukan pemugaran kembali secara menyeluruh dengan tidak merubah makna sebagai basic moral yang tertanam dalam nilai eksistensi istana dalam lokal Sumbawa.
\end{abstract}

Kata Kunci: Modernisasi, Arsitektur Tradisional, Istana Dalam Loka

\section{PENDAHULUAN}

Arsitektur tradisional merupakan basic kekuatan budaya yang tumbuh dan berkembang seiring dengan pola perkembangan kehidupan suku dan bangsa. Dalam arsitektur tradisional tersebut, terwujud suatu warisan budaya yang ideal sehingga wujud material dari suatu kebudayaan dapat dikhayati dan diamalkan oleh masyarakat. Dengan demikian itu, wujud material itu akan melahirkan rasa cinta terhadap arsitektur budaya tradisional yang dibangun oleh leluhrnya.

Berangkat dari argumentasi ini, bahwa arsitektur dapat dipahami melalui metafora keindahan yang dapat dilihat dalam sudut pandang sastra social dengan karakteristik yang berbeda. Menurut naskah kuno sastra jawa dan kitab Buk Tana Samawa secara tegas menjelaskan bahwa relevansi antara lingkungan dan kehidupan budaya manusia. Dalam (Mardanas, 1985:7) menyatakan bahwa masyarakat tradisonal dalam proses tata kelolah wilayah dan bangunan secara popular dibangun atas dasar penikmat rasa estetika dan nilai seni. Akan tetapi lanjut mardanas, bahwa arsitektur bukan sematamata untuk pertama kali penikmat rasa estetika bangunan yang kemudian sebagai basic utama kelangsungan hidup secara kosmis.

Arsitektur tradisional budaya local Sumbawa mempunyai cirri khas dengan unsur-unsur estetika dalam hiasan yang digunakan pada rumah tradisional adalah perpaduan antara flora dan fauna. Secara 
konseptual, bahwa arsitektur masyarakat tradisional Sumbawa (Tana' Samawa) berdasarkan suatu pandangan hidup ontologis dalam memahami alam semesta secara universal. Filosofi hidup masyarakat tradisional Sumbawa yang disebut "Salimpat" (empat unsure) menjadikan sebagai penyempurnaan identitas diri. Dalam filosofi itu menurut (Tato, 2008:2), menyatakan bahwa segala aspek kehidupan manusia barulah sempurna, jika terbentuk segi empat, yang merupakan mitos asal kejadian manusia yang terdiri dari empat unsure, yaitu Tanah, air, api, dan angin.

Dalam kontek itu, masyarakat tradisional Sumbawa memilki konsep pemahaman struktur pelapisan alam dalam tiga bagian kosmos, yaitu alam bawah, alam tengah dan alam atas. Oleh karena itu aspek rumah tradisional masyarakat suku Sumbawa yang tersusun dalam tiga tingkatan dan berbentuk segi empat, dibangun dengan pola mengikuti bentuk kosmos menurut kepercayaan masyarakat Sumbawa. Argumentasi ini, dibangun berdasarkan bahwa alam raya tersusun dalam tiga tingkatan, 1) Nene Pang Bao Awan Pitu (diatas langit ke tujuh) yaitu dimana dewadewa di pimpin oleh seorang dewa tertinggi yang bersemayam di langit ke tujuh yang disebut Nene Kuasa (dewa tunggal), 2) Pang Tengah adalah wakil-wakil dewa tertinggi yang menghuni di bumi dan bertugas mengatur hubungan manusia dengan dewa tertinggi serta mengawasi tata tertib jalannya roda kosmos, 3) Pang Bawa merupakan bentuk kosmos yang paling bawah dan berkaitan dengan pembuatan atau pembangunan rumah harus disasrkan pada kosmologis, dan diungkapkan dalam makna simbolis-simbolis yang diturunkan secara turun temurun (Hamid, 1978:12).

Istanah tua (dalam loka) adalah bentuk arsitektur tradisional di Sumbawa tercermin dalam warisan budaya dan perlu dilestarikan untuk mempertankan keragaman budaya bangsa. Dan oleh sebab itu, perlu dilakukan pengkajian guna mengungkapkan warisan budaya masa lampau sebagai symbol kejayaan kerajaan Sumbawa pada masa lalu. Masalah yang di teliti dalam penelitian ini adalah sejarah dan bentuk arkeologis Dalam Loka (istanah tua) sebagai icon rumah adat masyarakat Sumbawa dan esensi arsitektur dalam istanah (dalam loka). Penelitian ini menggunakan metode deskriptif dengan penedekatan kualitatif tentang pembaharuan terhadap Istana Tua (dalam loka). Adapun data dalam metode penelitian ini terdiri dari data primer dan data sekunder, sedangkan teknik pengumpulan data dilakukan dengan cara teknik pengamatan, wawancara, dan studi pustaka. Setelah data terkumpul, maka kemudian dianalisis dan dideskriptif.

\section{METODE PENELITIAN}

Penelitian ini adalah untuk mengetahui terjadi pembahuruan terhadap arsitektur tradisional istana tua (dalam loka) di sumbawa yang telah menjadi warisan budaya masyarakat sumbawa secara turun temurun. Pengkajian ini, dilakukan dengan metode deskriptif kualitatif. Sedangkan dalam tahap pengumpulan data dilakukan observasi lapangan dengan para tokoh-tokoh sejarah Sumbawa dan tukang yang pernah membangun istana (dalam loka) Sumbawa. Hasil dari observasi dan wawancara akan didukung oleh studi pustaka. Penelitian ini cenderung menggunakan analisis dengan pendekatan induktif yang disusun dalam bentuk narasi yang bersifat kreatif dan mendalam untuk dapat dijelaskan melalui langkah: heuristik, kritik, interprestasi, dan historiografi (Heriyono, 1995).

1. Tahapan Penelitian

a. Tahap observasi

Tahap pertama yang dilakukan dalam penelitian ini adalah observasi lapangan dilakukan untuk mengumpul data dengan cara memfoto, mengukur, membuat sketsa istanah (dalam loka) Sumbawa. Untuk Objek penelitian dilakukan Rumah Adat Istanah Tua (dalam loka) yang berlokasi di Kelurahan Seketeng, Kabupaten Sumbawa Besar.

b. Tahap Wawancara

Wawancara dilakukan untuk mengumpul data dengan menanyakan tokoh-tokoh yang mengerti tentang sejarah dan tokoh-tokoh yang terlibat 
dalam pembaharuan arsitektur tradisional istana (dalam loka) Sumbawa. Tahap ini diperlukan untuk mengumpul informasi-informasi yang akurat untuk mengkaji proses pembaharuan rumah adat tanah samawa. Berdasarkan hasil obserfasi lapangan, maka jenis data yang digunkan dalam penelitian ini adalah data primer dan data sekunder. Sumber data primer diperoleh melalui wawancara tokoh-tokoh yang ada di masyarakat, seperti tokoh adat, tokoh agama, tokoh masyarakat.

c. Tahap studi pustaka

Studi pustaka dilakukan data yang diperoleh data dari peneliti terdahulu dan buku, jurnal, artikel maupun laporan yang berkaitan dengan judul penelitian yang mau diteliti.

d. Tahap analisis

Tahap ini dilakukan utnuk menganalisis apabila dari ketiga tahap di atas sudah dilakukan. Maka datadata yang diperoleh, kemudian di analisa berdasarkan variable penelitian yang nantinya akan di teliti mana yang valid dan tidak valid untuk diteruskan dalam bentuk penulisan. Dalam proses analisis data dalam penelitian ini menurut (Moleong, 2014) dilakukan dengan cara sebagai berikut:

2. Reduksi data

Proses reduksi data yaitu, memilih atau menyeleksi data yang sudah terkumpulkan lalu memasukan kedalam tema, kategori, fokus, atau permasalahan penelitian. Data yang diperoleh ditulis dalam bentuk laporan atau data yang terperinci. Laporan yang disusun berdasarkan data yang diperoleh direduksi, dirangkum, dipilih pada hal-hal yang pokok, difokuskan pada hal-hal yang penting.

3. Display data

Proses display data yaitu penyajian data kedalam sejumlah matriks yang sesuai, misalnya matriks urutan waktu, matriks jalinan, dan lain sebagainya. Dengan kata lain proses ini adalah proses pengurutan data sesuai dengan waktu kejadian dan hal-hal yang memiliki keterkaitan untuk mendapatkan suatu interprestasi terhadap data penelitian. Dengan demikian, hal yang paling sering digunakan untuk menyajikan data dala penelitian kualitatif adalah dengan teks naratif.

4. Conclution Data

Proses conclution data yaitu penyimpulan data yang terkumpul dengan pelukisan atau penurutan tentang masalahmasalah yang dibahas dalam penelitian. Penyimpulan adalah memberikan kesimpulan-kesimpulan terhadap Datadata yang telah tersusun rapi menjadi tulisan yang benar tergolong komprehensif dan mendalam. Setelah sumber-sumber sejarah dikumpulkan maka kegiatan selanjutnya adalah verifikasi atau lazim disebut juga dengan kritik sumber dalam memperoleh keabsahan sumber.

\section{HASIL DAN PEMBAHASAN \\ Sumbawa Pada Masa Kesultanan}

Latarbelakang sosial-historis bahwa masyarakat Sumbawa memiliki ragam budaya yang akan melahirkan kesadaran akan identitas sebagai bentuk peradaban dalam memperkaya khasana perbedaan latarbelakang kultur. Bentukan peradaban masyarakat tradisional Sumbawa tersimpan dalam pengetahuan kolektif masa lalu sebagai perwujudan nilai untuk diwariskan secara terus menerus oleh generasi mendatang. Peradaban Sumbawa memiliki cirri dalam bentuk arsitektur yang beragam dimulai dari yang tradisional, kolonial maupun yang modern. Menurut catatan sejarah bahwa Tanah Samawa (Sumbawa) memulai aktifitas sejarahnya sekitar abad ke 14 Masehi dengan menjalin hubungan politik bersama Dinasti Hayam Wuruk raja Majapahit dengan maha patihnya Gajah Mada (1350-1386). Dimana pada saat itu tanah Sumbawa disebut Dinasti Dewa Awan Kuning dengan wilayah kekuasaannya Jereweh, Taliwang, Seran dan raja terakhir adalah Dewa Maja Purwa. Pada saat yang sama kerajaan Dewa Awan Kuning menganut kepercayaa animisme (hinduisme) serta percaya pada kekuatan mistik yaitu roh 
nenek moyang. Namu seiring dengan perkembangan zaman kepercayaan animisme mulai ditinggalkan dan membuka diri dengan menerima islam sebagai agama terakhir.

Masuknya islam ditanah samawa sekitar abad ke 16 Masehi tepat pada tahun (15401550) Masehi melalui para mubaligh dan para niaga dari Demak yang pada saat itu menjadi pusat penyebaran islam di Asia Tenggara. Dan pada tahun (1623) tanah Sumbawa dibawah kekuasaan Dewa Maja Purwa ditaklukan oleh Sultan Alaudin raja Gowa dengan melakukan exspansi guna mencari cadangan pangan ke seluruh pelosok pulau Sumbawa disatu sisi dan disisi lain menyebarkan agama islam. Proses islamisasi di kerajaan Sumbawa dilakukan dengan perkawinan silang antara putra dan putri mahakota kedua kerajaan, sehingga dengan demikian memudahkan proses interaksi dan pengenalaan islam bagi kerajaan Sumbawa yang bercorak hinduisme. Dengan hadirnya islam dalam kehidupan keagamaan masyarakat Sumbawa ikut merubah sistem pemerintahan yang bercorak kerajaan hindu berubah menjadi system kesultanan islam.

Dengan runtuhnya kerajaan Majapahit sehingga mengakibatkan berdirinya kerajaankerajaan kecil di tanah samawa menjadi kerajaan yang merdeka akibat tekanan dan pengaruh kerajaan majapahit yang menganut kepercayaan hindu. Dalam kondisi yang demikian itu menjadi sebuah langkah bagi para mubaligh untuk memperkenalkan islam terhadap masyarakat Sumbawa. Melalui kerajaan Dewa Maja Purwa (Utan) yang terakhir kali menganut agama islam membuat nota kesepakatan dengan Kerajaan Gowa dibawah pimpinan Karaeng Moroangang dengan hasil kesepakatan "Adat dan Rapang Samawa (contoh-contoh kebaikan) tidak akan diganggu gugat sepanjang raja dan rakyat menjalankan syariat islam". Setelaah wafatnya Raja Maja Purwa penerus tahta pemerintahan kerajaan Dewa Awan Kuning digantikan oleh Mas Goa untuk melanjutkan pengaruhnya. Pada masa pemerintahannya Mas Goa melanggar hasil kesepakatan yang yang dibuat oleh Raja Maja Purwa bersama Karaeng Moroangang untuk menjalaankan saryat islam seutuhnya. Pada tahun (1637)
Mas Goa diturunkan paksa oleh rakyatnya disebabka karena masih menganut pemahaman serta pengaruh hinduisme didalam lingkungan kerajaan dan beliau digantikan oleh Mas Dini. Setelah beberapa tahun menjalankan roda pemerintahan kerajaannya pada tahun (1684) Mas Dini digantikan oleh Mas Bantam yang merupakan pendiri kerajaan Sumbawa dari dinasti Dewa Dalam Bawa dengan gelar bangsawan Sultan Harun Arasyid I (1674-1702) melalui perkawinan silang dengan putri raja Gowa. Setelah itu pada tahun (1702) Masehi kerajaan Dewa Awan Kuning dipimpin oleh putra kedua Sultan Harunarrasyid I yang bernama Mas Madinah yang dinobatkan sebagai Sultan Jalaluddin Muhammadsyah I (1702-1723).

Berdasarkan "Adat Barenti Ko Syara dan Barenti Ko Kitabullah" sebagaimana yang tertuang didalam "Manik Kamutar Dewa Masmawa (Piagam) yang menjadi dasar dalam menjalakan roda pemerintahaannya. Tiga pokok utama Sultan Jalaluddin Muhammadsyah I mulai menanamkan pengaruhnya dengan menata dan mengatur system pemerintahan antara lain, 1), politik, keamanan, dan pertahanan, 2), Kemakmuran Rakyat, dan, 3), Ketakwaan Kepada Allah swt. Pada masa pemerintahannya beliau membangun istana yang diberi nama "Istana Bala Balong). Untuk menjaga kerajaan bebas dari pengaruh dan terlepas dari pengontrol penjajah, maka Sultan Muhammad Jalaluddin Syah I memimpin perang dan berjihat untuk mengusir serdadu penjajahan dari tanah Samawa. Dalam peperangan tersebut yang semakin senggit diperparah dengan gempuran kekuatan penjajah menyebabkan beliau wafat dalam perang itu.

Setelah mangkat Sultan Jalaluddin Muhammadsyah I, maka yang meneruskan tahta kerajaan adalah Riwabatang Datu Balasawo Dewa Loka Ling Sampar (17231725) yang merupakan kakak tertua dari Sultan Jalaluddin Muhammadsyah I. Pada kekuasaannya beliau meneruskan kebijakan yang dijalankan oleh sultan selama dua tahun sampai beliau wafat dan di makamkan di "Makam Sampar) yang kemudian mendapat nama Anumerta "Dewa Loka Ling Sampar". 
Wafatnya beliau menyebabkan kekosongan pemimimpin dalam kesultanan kerajaan, dan setelah itu berdasarkan musyawarah dan mufakat dari tua adat, maka akhirnya dinobatkan Jalaluddin Datu Taliwang yang bernama Dewa Ling Gunung Setia sebagai Sultan Sumbawa (1725-1731). Selama masa pemerintahannya Gunung Setia meneruskan kebijakan yang dibuat oleh Sulta Sultan Muhammad Jalaluddin Syah I dan pada saat yang sama terjadi kebakaran yang mengahanguskan Istanah Bala Balong yang dibuat pada masa pemerintahan Sultan Jalaluddin Muhammadsyah I.

Kebakaran itu menyebakan wafatnya Sultan Sumbawa beserta permaisuri dan keluarganya dan seluruh keluarga beliau di makamkan di bukit Gunung Setia yang kemudian diberi gelar Anumerta Datu Ling Gunung Setia. Setelah wafatnya Sultan Sumbawa Gunung Setia, maka penerus tahta kerajaan di gantikan oleh "Dewa Masmawa Sultan Muhammad Kaharuddin I (17311759). Pada masa pemerintahannya beliau membangun kembali istana yang sudah terbakar dan diberi nama Istana Gunung Setia. Sultan Muhammad Kaharuddin I dikenal sebagai pemimpin yang keras dan tidak mengenal kompromi terhadap penjajah Belanda. Sikap keras itu menjadi langkah jitu sultan untuk mengusir pemerintah hindia belanda dari bumi samawa. Pada tahun (1759) Sultan Muhammad Kaharuddin I wafat maka berdasarkan garis keturunan diangkatnya Dewa Masmawa Sultanah Siti Aisyah (17591761). Pada masa perintahannya sering terjadi pereteruan dengan para menteri dan pejabat kesultanan yang menyebabkan Sultanah Siti Aisyah diturunkan dari tahta kerajaan. Setelah itu digantikan oleh "Dewa Masmawa Lalu Onye Datu Ungkap Sermin Dewa Lengit Ling Dima (1761-1762) yang merupakan putra Datu Seppe yang berasal dari keturunan Harunarrasid I. Beberapa tahun memimpin kerajaan Lalu Onye meninggalkan tahta dengan alasan mencari suaka ke Bima.

Selanjutnya setelah Lalu Onye meninggalkan tahta kesultanan, maka digantikan oleh Dewa Masmawa Sultan Muhammad Jalaluddinsyah II (1762-1765) yang berasal dari banjar. Pada masa kekuasaannya beliau mampu mengenadalikan dan meredam ketegangan yang menyebabkan sering terjadinya konflik diantara kesultanan, selain itu beliau juga berjasa dalam membasmi perompak diperairan Sumbawa disatu sisi dan disisi yang lain beliau melakukan reformasi dan peninjauan kembali terhadap kitab hukum pidanan dan ketentuanketentuan lainnya. Setelah wafatnya Muhammad Jalaluddinsyah II maka kekuasaan jatuh ketangan Sultan Mahmud (1765), namun karena umurnya yang masih kecil sehingga yang menjalankan roda pemerintahan ditunjuklah Datu Taliwang Dewa Mappaconga yang bernama Mustafa. Dalam catatan sejarah Kitab Bo bahwa Sultan Mahmud tidak pernah duduk di tahta singgasana kesultanan meskipun sudah dilantik menggantikan ayahnya. Penetapan Mustafa sebagai kesultanan menimbulkan rasa sakit hati bagi datu-datu yang lain karena cara memilih tidak sesuai dengan hokum adat sehingga raja-raja dibagian timur Sumbawa bekerja sama dengan belanda untuk membatalkan pengangkatan Mappacong Mustafa.

\section{Studi Historis Arkeologi Arsitektur Tradisional Istana Tua (dalam loka)}

Latar belakang historis berdirinya arsitektur tradisional Istana Dalam Loka Sumbawa adalah rumah tinggal keluarga kerajaan yang dibangun oleh Sultan Muhammad Jalaluddinsyah III (1883-1831) yang merupakan sultan ke-16 dari dinasti Dalam Bawa. Berdasarkan akte yang tertanggal 18 agustus 1885 dari pemerintahan colonial Belanda yang memutuskan Sultan Muhammad jalaluddinsyah III untuk menjadi penguasa di kerajaan Sumbawa dan pada saat itulah pemerintah colonial belanda secara de facto berada di wilayah kesultanan Sumbawa. Arstektur rumah adat tradisional Istana Dalam Loka dibangun pada tahun (1885) dengan pekerjaan dibawah kendali Imam Haji Hasyim yang didesain menggunakan struktur istana yang diadopsi dari arsitektur mode Balla Lampoa di Goa. Bangunan Istana Dalam Loka berbentuk rumah panggung dengan luas bangunan $904 \mathrm{M}$ persegi dengan bahan kayu yang sebagian besar adalah kayu jati. 
Desain arsitektur Istana Dalam Loka dipengaruhi oleh kuatnya pengaruh islam yang masuk di diwilayah kesultanan Sumbawa ikut mengubah tatananan kehidupan masyarakat yang kemudian larut dalam norma dan nilai-nilai syariat islam. Dalam Loka memiliki makna yang tersirat dalam ungkapan kata (Dalam yakni Istana) dan (Loka yang berarti Dunia). Dalam Loka adalah rumah panggung kembar menghadap ke selatan yang berdiri kokoh, kuat, dan megah dengan 99 tiang yang terkandung dalam (Usma'ul Husna) yaitu 99 sifat allah mengandung makna dengan dapat memberikan suasana kesejukan, tentram, damai, aman, dan nyaman. Istana Dalam loka dibangun untuk menggantikan Istana yang terbakar pada masa kesultanan Gunung Setia yang termuat dalam filosofi adat "Syara Barenti Ko Kitabullah" yang mengandung arti semua adat istiadat maupun nilai-nilai dalam kehidupan masyarakat Sumbawa dibangun berdasarkan pedoman pada syariat islam.

Dalam Loka merupakan saksi sejarah yang menggambarkan tentang implementasi syariat islam pada kesultanan Sumbawa. Dengan arsitektur tradisional dirancang menggunakan ornament dengan symbolsimbol ajaran islam dan bahkan pada rentang waktu proses pembuatan tercermin pada umur manusia di dalam kandungan yaitu Sembilan bulan 10 hari. Arsitektur ini memiliki dua atap yang berbentuk kembar dengan satu tangga naik yang berada ditengah depan menghadap selatan yang merujuk pada syarat rukun sholat yakni "Attahiyat". Bentukan ini dibuat untuk mengingatkan kepada keluarga kerajaan beserta rakyatnya agar selalu melaksanakan sholat waktu sehari semalam.

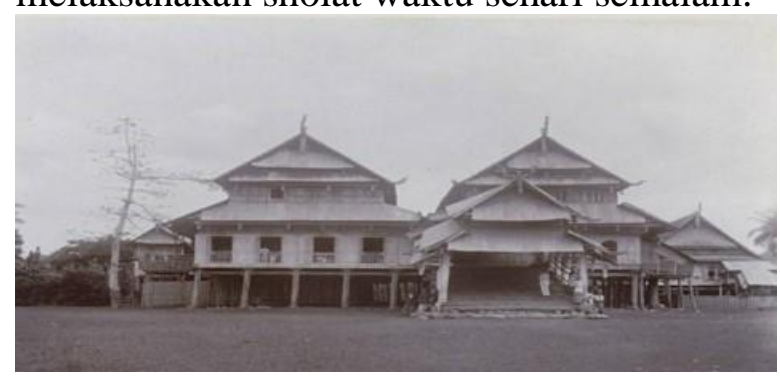

Gambar 1: Istana Tua Dalam Loka Sebelum Pemugaran Dok. Arsip Daerah

Istana Dalam Loka adalah arsitektur tradisional yang terbesar dan terdapat ruangan-ruangan yang cukup besar di dalamnya dengan memiliki fungsi antara lain, 1), Lunyuk Agung, berfungsi sebagai ruang untuk melangsungkan acara resepsi keluarga raja, musyawarah dan mufakat, 2), Lunyuk Mas, adalah ruang khusus untuk istri raja, istri menteri, dan pembantu penting kerajaan apabila dilakukan musyawarah dan mufakat, 3). Ruang Dalam, merupakan bagian dari ruangan untuk mengadu dan melapor setiap ada kegiatan yang dianggap perlu, 4), Ruang Dalam, ruang ini terdiri empat ruang kamar yang diperuntungkan untuk putra dan putri raja yang sudah berkeluarga, 5), Ruang Sidang, runag ini pada malam hari digunakan untuk tempat tidur para dayang, 6), Ruang Dapur, ruang ini berfungsi untuk menyiapkan makanan para penghuni istana, 7), Kamar Mandi, 8), Bala Bule, merupakan ruang dua susun, untuk lantai pertama digunakan untuk bermain putra dan putri mahakota, sedangkan lantai kedua tempat untuk menyaksikan permainan dan pertunjukan di luar istana, sedangkan dihalaman istana terdapat tempattempat penting dimulai dari kebun (keban alas), rumah jam (lonceng), kandang kuda dan mesjid.

\section{Pemugaran dan Modernisasi Arsitektur Istana Dalam Loka}

Istana Dalam Loka merupakan rumah panggung berskala besar, modern dan indah yang berdiri kokoh, kuat dan tahan lama berada di jantung kota Kabupaten Sumbawa dengan menghadap keselatan. Bangunan ini didesai menggunakan ornament yang khas dengan rumah adat Gowa Makassar. Secara arsitektur, unusur-unsur yang digunakan adalah kayu dengan menggunakan struktur rangka berupa tiang dan balok yang berukuran besar yang dipasang secara teratur sebagai penyanggah kekuatan.. Bentuk strukturnya menonjol dengan skala megah dan secara vertikal bangunan terdiri dua lantai diantara lantai satu menyatu dengan dua bagian bangunan sedangkan lantai dua terpisah antara bagian barat dengan timur bangunan. Ornament dalam arsitektur tradisional Istana Dalam Loka tidak dihiasi dalam bentuk lukisan yang menghiasi kayukayu bangunan ini. Hampir seluruh bagian 
kayu yang digunakan berbentuk polos tanpa ukiran dan cat.
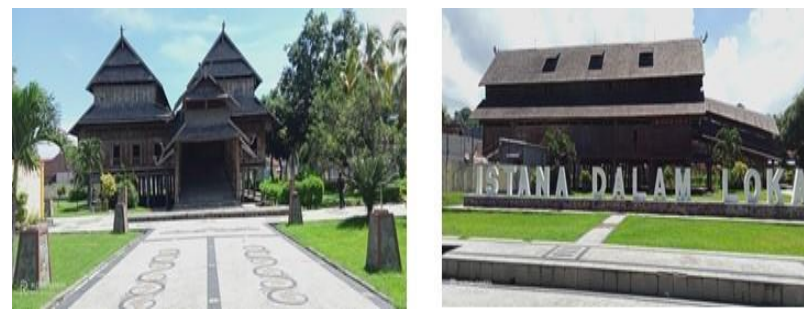

Gambar 2: Istana Tua Dalam Loka Hasil Pemugaran Dok. Pribadi

Berdasarkan hasil pengkajian dan penilaian oleh tim Balai Pelestraian Cagar Budaya Bali, NTB, dan NTT bahwa Istana Dalam Loka memiliki tingkat kerusakan cukup signifikan dan perlu dilakukan pelesetarian. Proses pelaksanaan pemugaran arsitektur tradisional ini disebabkan karena factor umur yang sudah tua dengan kedudukan bangunan yang miring, retak, pelapukan dan rapuh yang tidak memungkinan untuk mempertahankan. Komponen-komponen kayu bangunan harus diganti demi melestarikan kedudukan situs cagar budaya sebagai warisan sejarah yang secara terus menerus dipertahankan untuk kepentingan bangsa dan Negara. Dalam pelaksanaan pemugaran menurut Undangundang RI No. 11 tahun 2010 tentang pelestarian cagar budaya dengan ketentuan dapat dipertanggungjawabkan secara akademis dan berkoordinasi dengan ahli arkeologi untuk memperhatikan etikan dan ekstensi bangunan.

Pemugaran dilakukan untuk mengembalikan kondisi fisik bangunan cagar budaya yang rusak dengan ketentuan dengan tidak mengubah, menggeser, apalagi memindahkan benda purbakala ke tempat lain. Pemugaran bangunan arsitektur tradisional Istana Dalam Loka dilakukan pada tahun 1994 untuk menjaga kerusakan dengan cara memperbaiki, memperkuat, dan mengawetkan terhadap bahan-bahan bangunan yang digunakan melalui rekonstruksi, konsolidasi, rehabilitasi, dan restorasi. Hal ini merupakan serangkaian kegiatan dan upaya perbaikan pemulihan yang bertujuan untuk menjaga keaslian, bentuk bangunan, memperlambat proses kerusakan yang dapat dipertanggungjawabkan secara ilmiah.

Adapun hasil pemugaran Istana Dalam Loka dimulai dari 1), Pondasi, bertujuan untuk alas tiang bangunan agar tidak bersentuhan langsung dengan tanah. Awalnya pondasi menggunakan batu kali berbetuk bulat, namun setelah terjadi pemugaran maka batu kali digantikan menjadi semen beton yang lebih tinggi agar tidak tergenang resapan air sehingga menyebabkan kerusakan terhadap ujung bawah tiang. 2), Kemiringan, bangunan Istana Dalam Loka memiliki 99 tiang dengan menggunakan kayu jati yang masih asli dan tidak berubah, sedangkan tiang penyanggah sebagai rekonstruksi atap menagalami pergantian. Sebelumnya bangunan rumah panggung ini mengalami kemiringan akibat tekstur bangunan bagian bawah terjadi penurunan posisi yang kemudian kemiringan itu di angkat menjadi berdiri tegak lurus setelah terjadi pergantian kayu yang mengalami kerusakan. 3), Lantai, pada saat dibangunnya istana dalam loka, lanta menggunakan papan kayu biasa yang didatangkan dari daerah pelosok Sumbawa, namun setelah adanya pemugaran, lantai mengunakan kayu jati yang berukuran $3 \times 30$ $\mathrm{cm}$ disusun secara satu kesatuan yang rapih. 4), Dinding, berdasarkan analisa arkeologi bahwa dinding mengalami perubahan secara total yang awalnya terbuat dari perpaduan antara kayu bambu dengan kayu papan dan setelah terjadi renovasi maka dinding diganti menjadi kayu jati dengan ukuran $6 \times 11 \mathrm{~cm}$ dan ketebalan $2 \mathrm{~cm}$ serta lebar $30 \mathrm{~cm}$. 5) Atap, atap memiliki dua bagian yang terpisah yang pada awal berdirinya menggunakan seng yang didatangkan dari Singapura dan setelah terjadinya kerusakan serta banyak yang bocor menyebabkan air hujan masuk kedalam rumah sehingga atap yang menggunakan seng di ganti menjadi lapisan kayu uli yang didatangkan dari Daerah Kalimantan.

\section{KESIMPULAN}

Arsitektur tradisional Istana Tua (dalam loka) merupakan warisan cagar budaya yang dibangun pada masa Kesultanan Muhammad Jalaluddinsyah III (1883-1931). Istana dalam loka adalah rumah panggung besar yang 
berdiri kokoh, kuat, dan modern berlantai dua berpusat di tengah kota Kabupaten Sumbawa dengan luas bangunan 696,98 meter persegi dan memiliki 99 tiang penyanggah. Berdasarkan hasil pengkajian penilaian dari Balai Purbakala dan Arkeologi Bali, NTB, dan NTT bahwa Istana Tua (dalam loka) mengalami tingkat kerusakan yang cukup parah dengan kondisi kemiringan dan proses pelapukan terhadap kayu-kayu sehingga perlu dilakukan upaya pemugaran dan pengangkatan kembali terhadap rumah adat tersebut. Pemugaran arsitektur ini dilakukan $90 \%$ kecuali tiang yang masih asli, sedangkan unsure-unsur lain dimulai dari pondasi, lantai, dinding, tiang penyangga atap lantai dua, dan atap mengalami pergantian.

\section{SARAN}

Penelitian ini lebih menjelaskan tentang pemugaran kembali terhadap rumah adat tradisional Arsitetur Tradisional Dalam Loka akibat kerusakan dan pelapukan kayukayu dengan tingkat kerusakan yang cukup signifikan. Adapun syaran dari penulis adalah untuk tidak merubah dari bentuk keaslian arsitektur tradisional sehingga tidak terkesan menghilangkan nilai-nilai sejarah yang terkadung di dalamnya. Penulis menyadari bahwa karya tulis ini bukanlah hal yang baru namun sudah ada penulis-penulis terdahulu yang menulis tentang rumah adat Istana Dalam Loka di Sumbawa. Untuk itu penulis menyarankan agar penulis selanjutnya dapat menjelaskan secara objektif dalam mengungkapkan situs-situs sejarah.

\section{UCAPAN TERIMAKASIH}

Dengan terlaksananya penelitian ini tidak lupa kami selaku tim peneliti mengucapkan terima kasih kepada Kementerian Pendidikan dan Kebudayaan (Kemendikbud) Lembaga Pelayanan Pendidikan Tinggi Wilayah VIII (LLDIKTIVIII) atas pemberian dana penelitian, sehingga penelitian ini bisa terlaksana sesuai dengan waktu yang ditetapkan.

\section{DAFTAR PUSTAKA}

Chairil B. Amiuza, 2017. Semiotika Arsitektur Tradisional Sumbawa. Jurnal RUAS, Vol. 2
Henny Gambiro, Ahmad Yamin, 2018. Meneropong Istanah Tua (Dalam Loka) Warisan Arsitektur Tradisonal Sumbawa. Sumbawa Besar: Jurnal Arsitektur Bangunan \& Lingkungan.

I Nyoman Sumartika, dkk, 2010. Purnapugar Istana Dalam Loka. Balai Pelestarian Peninggalan Purbakala Bali, NTB, dan NTT

Koentjaraningrat, 1983. Pengantar Ilmu Antropologi, Jakarta

Maryono Irawan, 1985. Pencermin Nilai Budaya Dalam Arsiterkur Indonesia, Jakarta: Penerbit Jambatan.

Rahil Muhammad Hasbi, 2017. Kajian Kearifan Lokal Pada Arsitektur Tradisional Rumah Aceh, Aceh: Jurnal Arsitektur Bangunan \& Lingkungan Univesitas Marcu Buana.

Ricky FS. Rumagit, 2015. Arsitektur Tradisional Orang Kaili, Kementrian Pendidikan dan Kebudayaan Direktoral Jenderal Kebudayaan.

Saing A. M. 2010. Arsitektur Tradisional Rumah Adat Bugis Makassar. Makassar: Indira Art

Sardjono, Nurdin, Agung, 2011. Arsitektur Dalam Perubahan Kebudayaan. Doktor Teknik Arstektur Perkotaan.

Soerjono Soekanto, 1982. Pengantar Ilmu Sosiologi, Jakarta: Penerbit Rajawali Pers

Zain, Zairin, 2012. Pengaruh Aspek Eksternal Pada Rumah Melayu Tradisional di Kota Sambas Kalimantan Barat. Jurnal IPS Vol. 4 